\title{
Prevalence of depression and its risk factors among patients with chronic obstructive pulmonary disease in a tertiary level hospital in West Bengal, India
}

\author{
Kalyan Bhowmik', Moniruzzaman ${ }^{2}$, Anjan Adhikari $^{3}$, Shahnaz Choudhury ${ }^{4}$, MSA Mansur Ahmed ${ }^{5}$ \\ ${ }^{1}$ Student of MPhil Programme in Noncommunicable Disease (NCD), ${ }^{2}$ Senior Lecturer, ${ }^{4}$ Assistant Professor, ${ }^{5}$ Head and Course \\ Chairman, NCD, Department of Community Medicine, Bangladesh Institute of Health Sciences (BIHS), Dhaka, Bangladesh. \\ ${ }^{3}$ Assistant Professor, Department of Pharmacology, RG Kar Medical College, Kolkata, India.
}

\begin{abstract}
In recent years, chronic obstructive pulmonary disease (COPD) has increased several folds in the developing countries and the disease is accompanied with several co-morbidities among which depression is a major one. Still now there is a lack of data regarding the prevalence and risk factors of depression among the patients with COPD in India. The aim of the study is to assess the prevalence of depression and associated risk factors in patients with COPD in Kolkata, India. In this cross-sectional study, 214 COPD patients were selected by purposive sampling at OPD of Pulmonary Medicine, RG Kar Medical College, Kolkata, India. The patients were diagnosed and grouped into different stages of COPD by clinical examination and spirometry. A questionnaire was administered among the respondents to collect the data regarding their socio-demographic conditions followed by Patient Health Questionnaire 9 (PHQ-9) to measure the level of depression. The mean age of the respondents was $59.37 \pm 11.37$ years and $99 \%$ were male. The proportion of depression among patients with COPD was $86 \%$. Among the respondents, $36.9 \%$ had moderately severe depression, $32.2 \%$ had moderate depression and $6.1 \%$ had severe depression. The risk factors of depression among COPD patients were urban residence ( $\mathrm{OR}=4.79, p=0.02)$, income group of 5000-9999 Rupees per month $(\mathrm{OR}=18, p=0.38)$, teetotalers $(\mathrm{OR}=8.36, \mathrm{p}=0.02)$, Stage $2 \mathrm{COPD}(\mathrm{OR}=83, p=0.001)$ and onset of $\mathrm{COPD} \geq 70$ years of age $(\mathrm{OR}=20, p=0.02)$. The study showed that more than 8 out of 10 COPD patients and it can be considered very high proportion. The study highlight the importance of routine screening for depression of all COPD patients in all healthcare settings and implementation of effective strategies for proper prevention and management of depression in those patients.
\end{abstract}

Keywords: Depression, COPD, Prevalence, Risk factors, India.

\section{Introduction}

Chronic obstructive pulmonary disease (COPD) is one of the leading non-communicable diseases and a leading cause of morbidity and mortality. In 1990, COPD ranked the sixth most common cause of death worldwide and is predicted to become the third most common cause of mortality and the fifth most common cause of chronic disability by $2020^{1}$. More than 3 million people died of COPD in 2005, which is equal to $5 \%$ of all deaths globally that year and almost $90 \%$ of COPD deaths occurred in low- and middle-income countries. ${ }^{2}$ According to the 2007 estimation of World Health Organization (WHO), 210 million people have COPD. ${ }^{3}$

The burden of COPD in Asia is currently greater than that in developed Western countries linked to the epidemic of tobacco exposure and indoor and outdoor air pollution in Asian countries. ${ }^{4}$ Total deaths from COPD are projected to increase by more than $30 \%$ in the next 10 years without interventions to cut risks, particularly exposure to tobacco smoke. $^{2}$

In India, prevalence rates of COPD vary from 2 to $22 \%$ in men. ${ }^{5}$ There were some variations in prevalence rates depending upon the place of residence and

\section{Practice Points}

- COPD is one of the commonest noncommunicable diseases and a leading cause of morbidity and mortality.

- There is lack of research regarding the prevalence and risk factors of depression among the patients with COPD in India.

- The prevalence of depression among COPD patients was $86 \% ; 36.9 \%$ had moderately severe depression, $32.2 \%$ had moderate depression and $6.1 \%$ had severe depression.

- The risk factors of depression among COPD patients were urban residence, income, teetotalers, stage 2 COPD and time of onset of COPD.

- Routine screening for all patients and appropriate management and prevention strategies are necessary to overcome depression in COPD patients.

Correspondence: Dr Kalyan Bhowmik, RM-5, Rental Housing Estate, 193 Andul Road,Howrah 711109, West Bengal, India. E-mail: kalikalyan@yahoo.co.in.

South East Asia Journal of Public Health 2012;2(2):34-40. (C) 2012 Bhowmik et al., publisher and licensee Public Health Foundation Bangladesh. This is an Open Access article which permits unrestricted non-commercial use, provided the original work is properly cited. 
socio-economic groups but significant differences were observed in relation to the smoking habit and exposures to combustion of solid fuels and environmental tobacco smoke. ${ }^{6}$ The prevalence of COPD is estimated as $4.1 \%$ in India. ${ }^{7}$ More than $80 \%$ of these patients are not diagnosed and therefore they are not treated appropriately. ${ }^{8}$

The natural course of COPD is complicated by the development of systemic consequences and comorbidities. ${ }^{9}$ These may be major features in the clinical presentation of COPD. Systemic consequences may be defined as non-pulmonary manifestations of COPD with an immediate cause-and-effect relationship, whereas comorbidities are diseases associated with COPD. Depression is regarded as one of the major co-morbidities of COPD. ${ }^{9}$ Evidence from a study has shown that depression is related to the outcome of emergency treatment in patients with COPD. ${ }^{10} \mathrm{~A}$ few studies were conducted to find out the prevalence of depression among COPD patients and the results were variable. A systemic review conducted on different studies remains inconclusive regarding the prevalence of depression in patients with COPD. ${ }^{11}$ The proportion of depression among the patients with COPD can demonstrate how depression can affect the life of a patient with chronic obstructive pulmonary disease. ${ }^{9}$ In India, a number of studies were conducted to find out the prevalence of depression in population and a study from urban South India estimated the prevalence of depression is $25.7 \%$ among the people above 60 years of age. ${ }^{12}$

There are limited on depression among patients with COPD in India. A study ${ }^{13}$ conducted in Bhopal demonstrated the prevalence of depression among patients with COPD patients is $72 \%{ }^{13}$ There is inadequate data regarding the risk factors of depression among patients with COPD and exploration of these risk factors is required for further management of the patients. The presence of un-recognized sub-clinical depression in patients with COPD is a major concern, as they are at risk of developing major depression. This may in turn increase the burden of physical disabilities in patients with COPD. There is still a gap of knowledge regarding the proportion of depression among patients with COPD in other parts of India. The aim of the study is to assess the prevalence of depression and associated risk factors in patients with COPD in Kolkata, India.

\section{Materials and methods}

A cross-sectional study was conducted at the R.G Kar Medical College and Hospital, Kolkata, India on patients with COPD attending the outdoor department of pulmonary medicine in the period between September 2011 and March 2012. Patients already under treatment of depression were excluded as antidepressant may affect the depression score. The seriously ill patients were also excluded.

The stage of severity of COPD was determined in all COPD patients and using spirometry according to GOLD standard. ${ }^{14} \mathrm{~A}$ questionnaire was administered to find out the socio-demographic and behavioral status of the patients. The Patient Health Questionnaire 9 (PHQ$9)^{15}$, a valid tool for screening depression ${ }^{16}$ was also used to measure the level of depression. We used the validated Bengali version of Patient Health Questionnaire 9 (PHQ-9). ${ }^{17}$ The severity of depression was classified according to the depression score of PHQ-9. ${ }^{15}$ The classification is as follows: none or minimal (0-4), mild (5-9), moderate (10-14), moderately severe (15$19)$, severe $(20-27)$.

\section{Statistical analysis}

The statistical analysis was done using Statistical Package for Social Sciences (SPSS) version 16. The prevalence of depression and other categorical variables were reported as proportion with $95 \%$ confidence interval (CI). The categorical data were compared by chi-square test followed by a logistic regression analysis at a significant level of 0.05 .

\section{Ethical approval}

The protocol was approved by the ethical review committee of the R G Kar Medical College and Hospital. All the participants were verbally informed about the name of the researcher, about the study objectives, procedures, and the risks and benefits involved. This information was sufficiently discussed with them and they were allowed to ask any information and clarification. All the participants selected, participate in the study, singed an informed consent and who are illiterate, their witness signature were used. They were informed about their right to withdraw from the study at any time without showing any cause. The participants were reassured about the confidentiality of data and the use of this data only for this research purpose. The questionnaires were kept securely. All the procedures were done with giving respect and dignity to the participants.

\section{Result}

Among the 214 respondents only 2 respondents were female. The mean age of the respondents was $59.37 \pm 11.4$ years. Two-thirds $(66.8 \%)$ respondents were from urban area and rest one-third (33.2\%) were from rural area (Table 1).

More than half of the respondents $(59.3 \%)$ were found to be ex-smoker, one-third of the respondents were regular smoker and only $8.4 \%$ (18) of the respondents were non-smoker. Around two-thirds of the respondents $(65.0 \%)$ were teetotalers and rest $(35.0 \%)$ was alcohol consumers. More than half of the respondents $(58.9 \%)$ were suffering from COPD for $0-4$ years. The proportion of the respondents in stage 2 COPD was highest $(45.3 \%)$ among the stages of COPD. The proportion in stage 1 and stage 3 were $32.2 \%$ and $22.0 \%$ respectively. Only $0.5 \%$ was in stage 4 . One-fifth of the respondents $(20.1 \%)$ were suffering from COPD for 5-9 years. Respondents suffering from COPD for 10-19 years and $\geq$ 20 years were $32.2 \%$ and $22.0 \%$ respectively. The mean age of onset of COPD among the respondents was $53.4 \pm 10.8$ years. Almost one-third $(29.0 \%)$ of the respondents had family history of COPD (Table 2). 
Table 1: Socio-demographic characteristics of the respondents

\begin{tabular}{|c|c|}
\hline Variables & Respondents (\%) \\
\hline \multicolumn{2}{|l|}{ Age groups (yrs) } \\
\hline $35-44$ & $19(8.9 \%)$ \\
\hline $45-54$ & $55(25.7 \%)$ \\
\hline $55-64$ & $63(29.4 \%)$ \\
\hline 65 and above & $77(36 \%)$ \\
\hline Mean age \pm SD (yrs) & $59.37 \pm 11.37$ \\
\hline \multicolumn{2}{|l|}{ Gender } \\
\hline Male & $212(99.1 \%)$ \\
\hline Female & $2(0.9 \%)$ \\
\hline \multicolumn{2}{|l|}{ Religion } \\
\hline Hinduism & $172(80.4 \%)$ \\
\hline Islam & $41(19.2 \%)$ \\
\hline Christianity & $1(0.5 \%)$ \\
\hline \multicolumn{2}{|l|}{ Marital status } \\
\hline Single & $19(8.9 \%)$ \\
\hline Married & $184(86 \%)$ \\
\hline Widow/widower & $11(5.1 \%)$ \\
\hline \multicolumn{2}{|l|}{ Educational level } \\
\hline No formal education & $73(34.1)$ \\
\hline Primary school level & $99(46.3 \%)$ \\
\hline Madhyamik (Secondary) & $13(6.1 \%)$ \\
\hline Higher Secondary & $17(7.9 \%)$ \\
\hline Graduation \& above & $12(5.6 \%)$ \\
\hline \multicolumn{2}{|l|}{ Residence } \\
\hline Rural & $71(33.2 \%)$ \\
\hline Urban & $143(66.8 \%)$ \\
\hline \multicolumn{2}{|l|}{ Occupational status } \\
\hline Service holder & $18(8.4 \%)$ \\
\hline Self -employed & $104(48.6 \%)$ \\
\hline Unemployed & $65(30.4 \%)$ \\
\hline Retired & $27(12.6 \%)$ \\
\hline \multicolumn{2}{|c|}{ Household income (Rupees/month) } \\
\hline $0-999$ & $7(3.3 \%)$ \\
\hline $1000-4999$ & $142(66.4 \%)$ \\
\hline $5000-9999$ & $41(19.3 \%)$ \\
\hline $10000-19999$ & $19(8.9 \%)$ \\
\hline 20000 and more & $5(2.3 \%)$ \\
\hline
\end{tabular}

The proportion of depression among patients with COPD was $86 \%$. Among the all respondents, $36.9 \%$ had moderately severe depression, $32.2 \%$ had moderate depression and only $6.1 \%$ had severe depression as shown in Figure 1. The mean PHQ score among all the respondents was $12.5 \pm 5.0$. The mean PHQ score among stage 1 COPD (mild), stage 2 COPD (moderate), and stage 3 COPD (severe) were $9 \pm 5.5,13.7 \pm 4.3$, and $15 \pm 3.7$ respectively. There was only one patient of stage 4 COPD (very severe) and his PHQ score was 17.0 (Figure 2). It was also found that the depression increases with the progression of the stages of COPD. The risk factors which are found to be involved with the development of depression among COPD patients were urban residence $(\mathrm{OR}=4.79, p=0.02)$, income group of 5000-9999 rupees per month $(\mathrm{OR}=18, \quad p=0.38)$,
Table 2: Behavioral characteristics and variables related to COPD of the respondents

\begin{tabular}{|l|c|}
\hline Variables & Respondents (\%) \\
\hline Smoking status & $69(32.3 \%)$ \\
\hline Regular smoker & $18(8.4 \%)$ \\
\hline Non-smoker & $127(59.3 \%)$ \\
\hline Ex-smoker & $75(35 \%)$ \\
\hline Alcohol consumption & $139(65 \%)$ \\
\hline Alcohol consumer & $69(32.2 \%)$ \\
\hline Teetotaler & $97(45.3 \%)$ \\
\hline Stages of COPD & $47(22 \%)$ \\
\hline Stage 1 & $1(0.5 \%)$ \\
\hline Stage 2 & $126(58.9 \%)$ \\
\hline Stage 3 & $43(20.1 \%)$ \\
\hline Stage 4 & $34(15.9 \%)$ \\
\hline Duration of COPD & $11(5.1 \%)$ \\
\hline $0-4$ yrs & $5.93 \pm 5.9$ years \\
\hline $5-9 y r s$ & $79(36.9 \%)$ \\
\hline $10-19 y r s$ & $120(56.1 \%)$ \\
\hline 20 yrs and above & $157 \%)$ \\
\hline Mean \pm SD & $53.4 \pm 10.8$ years \\
\hline Age of onset of COPD & $62(29 \%)$ \\
\hline $30-49$ & \\
\hline $50-69$ & \\
\hline$\geq 70$ & \\
\hline Mean \pm SD & \\
\hline Family history of COPD & \\
\hline
\end{tabular}

Teetotaler $(\mathrm{OR}=8.36, p=0.002)$, Stage $2 \mathrm{COPD}(\mathrm{OR}=83$, $p=0.001)$, and onset of COPD $\geq 70$ years of age $(\mathrm{OR}=20$, $p=0.022$ ) as shown in Table 3 .

\section{Discussion}

Among the major non-communicable diseases, COPD is the leading cause of morbidity and mortality and prevalence of COPD is rising particularly in the developing world. Co-morbid psychiatric illness accompanied with COPD can be a unique challenge in the treatment of COPD. The presence of unrecognized depression in patients with COPD can be a major concern, as they are at risk of developing major depression and may increase the burden of physical activity which turns into less productivity and poor quality of life.

The current study shows that the prevalence of depression among the COPD patients is very high and it indicates that more than 8 in every 10 respondents were suffering from depression. The prevalence of depression of the current study was in line with result of the study conducted by Dey ${ }^{13}$ in Madhyapradesh, which found that almost 7 out of 10 COPD patients were depressed. The same screening tool was used in that study and the mean age $(61.7 \pm 9.6$ years $)$ of the respondents of that study was nearly similar to the mean age $(59.3 \pm 11.6$ years) of the respondents of the current study. Kunik et $a l .{ }^{18}$ in the USA also found that 8 out of 10 patients with chronic breathing disorders had depression, anxiety or both. However, that study included all chronic breathing 


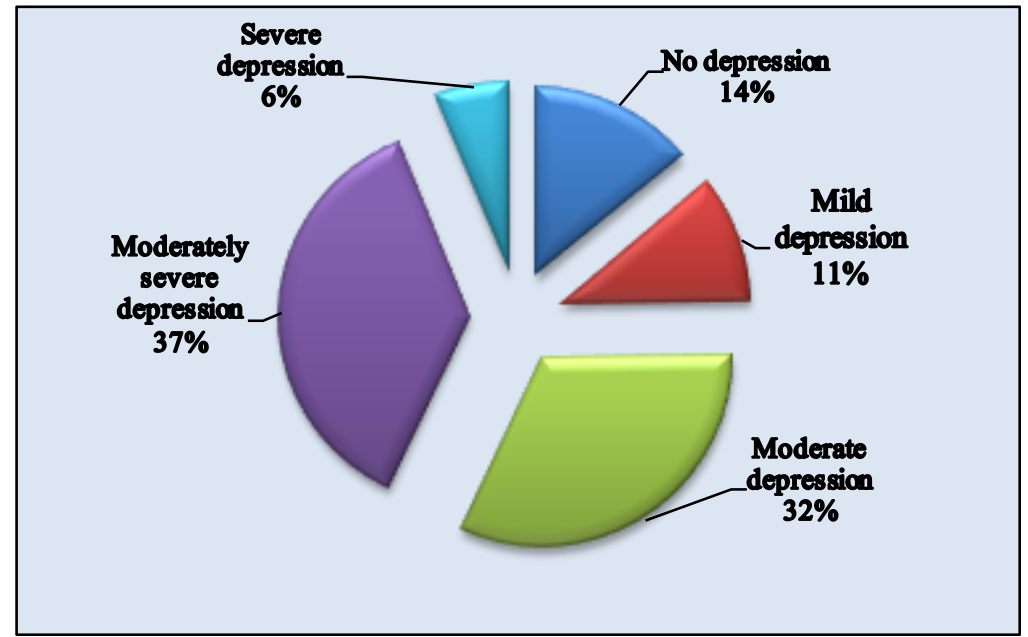

Figure 1: Level of depression among the respondents

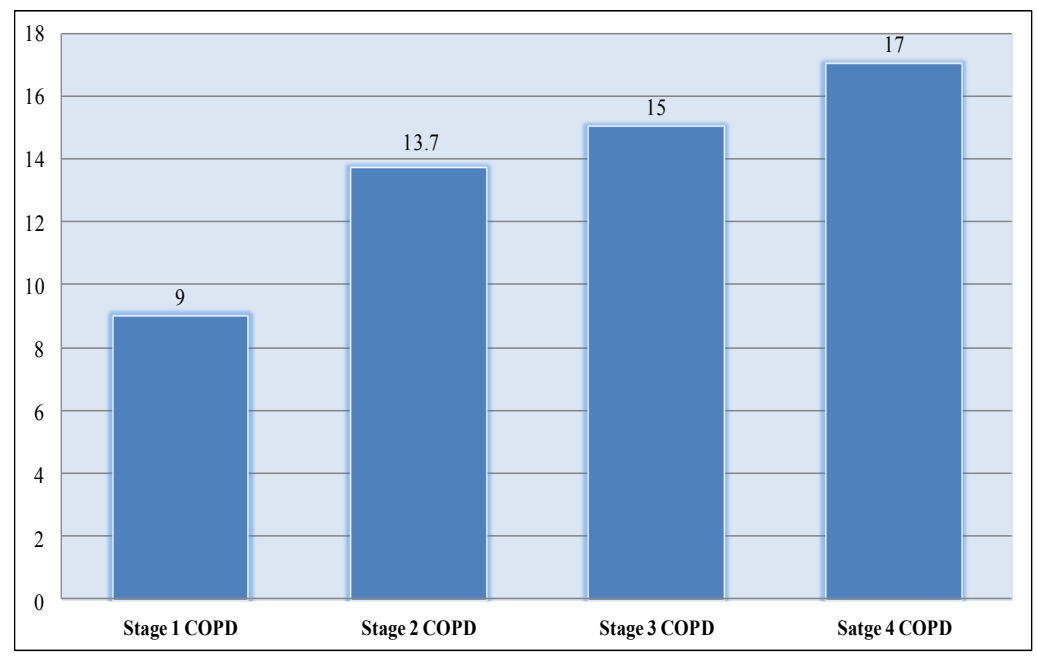

Figure 2: Distribution of mean PHQ-9 score among the different stages of COPD

disorders, namely, COPD, asthma and bronchiectasis. Solani et al. ${ }^{19}$ found the prevalence of depression to be $71.0 \%$ and that is comparable with the result of current study.

A study conducted by Dey ${ }^{13}$ found mean PHQ score of $14 \pm 7$, which was higher than that of our current study. In that study the mean PHQ score of stage 2 COPD and Stage 3 COPD were $13 \pm 5.4$ and 15.5 \pm 3.6 , which were in line of the present study.

The proportion of depression among the COPD patients, found in our study varied from the findings of Manen et $a l .{ }^{20}(25 \%)$ and Wagena et al. ${ }^{21}(22 \%$ to $37 \%$ ) - this may be due to the socio-cultural and economic differences between the Dutch population and Indian population and different health care delivery system. It is also to be mentioned that Manen et al. ${ }^{20}$ used Centers for Epidemiologic Studies Depression (CES-D) scale ${ }^{22}$ and Wagena et al..$^{21}$ used Dutch version of SCL-90-R ${ }^{23}$ for measuring the depression level.
The present study found that the depression increased significantly with the progression of COPD. Apart from it, the risk indicators which are determined from the current study are residence, alcohol consumption habit, educational level, income status, and age of onset of COPD. According to the finding of the current study, COPD patients those are of urban residence, income group of 5000-9999 rupees per month, teetotalers, stage 2 COPD and onset of COPD $\geq 70$ years are significantly more likely to develop depression. There are not much studies focusing on the risk indicators of depression among COPD patients in India and the only study by Dey $^{13}$ found that depression increases significantly with the progression of COPD and the finding corresponds with the present study. Manen et al. ${ }^{20}$ found that patients with mild to moderate COPD severity are not at increased risk for depression but patient with severe COPD had higher risk of depression. However, Wagena et $a l . .^{21}$ did not find any significant association between severity of COPD and level of depression. 
Table 3: Strength of association of a set of independent variables with status of depression

\begin{tabular}{|c|c|c|c|c|}
\hline \multirow[t]{2}{*}{ Independent variables } & \multirow[t]{2}{*}{ OR } & \multirow[t]{2}{*}{$P$-value } & \multicolumn{2}{|c|}{$95 \%$ CI for $\operatorname{Exp}(B)$} \\
\hline & & & Lower & Upper \\
\hline \multicolumn{5}{|l|}{ Age category } \\
\hline Age group (35-44) & 1.000 & & & \\
\hline Age group (45-54) & 3.024 & 0.424 & 0.200 & 45.610 \\
\hline Age group (55-64) & 2.075 & 0.339 & 0.465 & 9.258 \\
\hline Age group $(\geq 65)$ & 2.777 & 0.316 & 0.377 & 20.436 \\
\hline \multicolumn{5}{|l|}{ Residence } \\
\hline Rural & 1.000 & & & \\
\hline Urban & 4.794 & $0.027^{*}$ & 1.2 & 19.153 \\
\hline \multicolumn{5}{|l|}{ Educational status } \\
\hline Illiterate & 1.00 & & & \\
\hline Literate & 3.474 & 0.051 & 0.996 & 12.119 \\
\hline \multicolumn{5}{|c|}{ Household Income (rupees/month) } \\
\hline $0-999$ & 1.000 & & & \\
\hline $1000-4999$ & 1.246 & 0.749 & 0.324 & 4.796 \\
\hline $5000-9999$ & 18.568 & $0.038^{*}$ & 1.180 & 292.209 \\
\hline 10000-19999 & 0.572 & 0.532 & 0.099 & 3.295 \\
\hline$\geq 20000$ & 3.793 & 0.366 & 0.211 & 68.342 \\
\hline \multicolumn{5}{|c|}{ Alcohol consumption status } \\
\hline Alcohol consumer & 1.000 & & & \\
\hline Teetotaler & 8.36 & $0.002 *$ & 2.192 & 31.92 \\
\hline \multicolumn{5}{|l|}{ Hypertension } \\
\hline Hypertension absent & 1.000 & & & \\
\hline Hypertension present & 0.509 & 0.237 & 0.166 & 1.558 \\
\hline \multicolumn{5}{|l|}{ Stages of COPD } \\
\hline Stage 1 & 1.000 & & & \\
\hline Stage2 & 83.206 & $0.001 *$ & 6.151 & 1125.617 \\
\hline Stage 3 & 5.734 & 0.186 & 0.431 & 76.302 \\
\hline \multicolumn{5}{|l|}{ Age of onset of COPD } \\
\hline $30-49$ years & 1.000 & & & \\
\hline $50-69$ years & 3.496 & 0.155 & .623 & 19.622 \\
\hline$\geq 70$ years & 20.879 & $0.022 *$ & 1.554 & 280.459 \\
\hline \multicolumn{5}{|l|}{ Family History of COPD } \\
\hline Absent & 1.000 & & & \\
\hline Present & 2.573 & 0.096 & .845 & 7.835 \\
\hline Constant & 0.00 & 0.000 & & \\
\hline
\end{tabular}

* Significant

The risk factors found in the study of Schane et $a l^{24}$ were female gender, marital status, educational status, co-morbid diabetes, arthritis and difficulty in walking. This study was done in among the US population who were $\geq 50$ years of age. The current study had only 2 female respondents and hence no valid comparison could be done regarding the gender. Among the other risk factors, educational level was also found to be a risk indicator of our study. The variation among the risk factors of these two studies may be due to the difference of culture, economic condition and health-care facilities of the US population and Bengali population. Manen et $a l^{20}$ also found that living alone was a risk factor of depression among patients with COPD in Dutch population. This study, did not find any significant association of age, sex, education and co-morbidity with depression among COPD. These findings are in line with the findings of the current study.

In the current study teetotalers were found to be significantly more likely to develop depression than the alcohol consumers though alcohol use disorder is suggested to have a causal association with major depression. ${ }^{25}$ However, the study conducted by Tabak et al. ${ }^{26}$ among Dutch population from 1994 to 1997 showed the subjects with low alcohol consumption (1-3 g/day) had lower prevalence of COPD symptoms than the teetotalers and this finding may support the result of the current study.

The study has a number of limitations. Being a hospitalbased study, finding of this study may not be generalized and it may not give the actual proportion of depression among patients with COPD of the whole country. 
Moreover, diagnosis of COPD and staging of COPD were done by Spirometric test and the results were varied from different examiner's motivation and instructions provided to the patients. This may be resulted inter -examiner variation, which was not calculated. Recognition of co-morbid depression is difficult, because some of the physical symptoms of COPD may mimic the core symptoms of depression, for example, poor sleeping pattern, anorexia and loss of enjoyment due to breathlessness which may lead to overestimation of depression among COPP patients.

\section{Conclusion}

The study found that the proportion of depression among patients with COPD is $86 \%$ (more than 8 out of 10 patients) and it can be considered very high proportion. The study also confirmed the risk factors of developing depression in COPD patients were urban residence, income group (5000-9999 rupees per month), stage 2 COPD and onset of COPD $\geq 70$ years of age and abstinence from alcohol. The study found that proportion depression increases significantly with the progression of the stages of COPD. The study highlight the importance of routine screening for depression of all COPD patients in all healthcare settings and implementation of strategies for proper management and prevention of depression in those patients. Large scale studies should be conducted to examine the prevalence of depression among COPD patients and their risk factors in the other parts of the country. Awareness regarding depression among COPD patients should be enhanced especially for the health care professionals. Above all, national management guidelines for the depression among COPD patients should be developed and implemented.

\section{References}

1. Lopez AD, Murray CC. The global burden of disease 1990-2020. Nat Med 1998;4: 1241-3.

2. WHO. The global burden of disease: 2004 update. Geneva: World Health Organization, 2008.

3. World Health Organization. Chronic respiratory diseases: Burden of COPD. http://www.who.int/ respiratory/copd/burden/en/. (accessed Nov 2012).

4. Lopez AD, Mathers CD, Ezzati M, Jamison DT, Murray CJ. Global and regional burden of disease and risk factors, 2001: systematic analysis of population health data. Lancet 2006;367:1747-57.

5. Reddy KS, Gupta PC. Report on tobacco control in India. New Delhi: Ministry of Health and Family Welfare, Government of India, 2004.

6. Jindal SK, Agarwal AN, Chaudhry K, Chhabra SK, D'Souza GA, Gupta D, et al. Asthma Epidemiology Study Group. A multicentric study on epidemiology of chronic obstructive pulmonary disease and its relationship with tobacco smoking and environmental tobacco smoke exposure. Indian J Chest Dis Allied Sci 2006;48:23 -7 .

7. K .Jindal Surinder. Emergence of chronic obstructive pulmonary disease as an epidemic in India. Indian J Med Res 2006;124: 619-30.

8. Buist AS, McBurnie MA, Vollmer WM, Gillespie S, Burney $\mathrm{P}$, Mannino DM, et al. International variation in the prevalence of COPD (the BOLD Study): a population based prevalence study. Lancet 2007;370:741-50.

9. Decramer M, Rennard S, Troosters T, Mapel DW, Giardino N, Mannino D, Wouters E Sethi $\mathrm{S}$, Cooper CB. COPD as a lung disease with systemic consequences-clinical impact, mechanism, and potential for early intervention. COPD 2008;5:235-56.

10. Dahlén Inger, Janson Christer Anxiety and Depression Are Related to the Outcome of Emergency Treatment in Patients With Obstructive Pulmonary Disease. Chest 2002;122:1633-7.

11. L van Ede, C J Yzermans, H J Brouwer, Prevalence of depression in patients with chronic obstructive pulmonary disease: a systematic review, Thorax 1999;54:688-92.

12. Poongothai S, Pradeepa R, Ganesan A, Mohan V. Prevalence of depression in a large urban south Indian population: the Chennai Urban Rural Epidemiology Study (Cures-70). PLoS ONE 4 (9): e7185.

13. Dey S. Prevalence of depression in stable chronic obstructive pulmonary disease. Indian $J$ Chest Dis Allied Sci 2011 Jan-Mar;53:35-9.

14. Buist AS, Anzueto A, Calverley P, deGuia TS, Fukuchi Y, Jenkins C, Khaltaev N, et al. Global strategy for the diagnosis, management, and prevention of chronic obstructive pulmonary disease 2006. Global Initiative for chronic obstructive pulmonary disease. Bethesda (MD): Global Initiative for Chronic Obstructive Lung Disease (GOLD), 2006.

15. MacArthur Foundation Depression in Primary Care Initiative. http://www.depressionprimarycare.org. (accessed Nov 2012)

16. Kurt Kroenke, MD, Robert L Spitzer, MD,and Janet B W Williams, DSW .The PHQ-9 Validity of a Brief Depression Severity Measure.J Gen Intern Med 2001;16: 606-13.

17. Kochhar PH, Rajadhyaska SS,Suvarna VR for PRIME MD study group. Translation and Validation of brief patient health questionnaire against DSM IV as a tool to diagnose major depressive disorder in Indian patients. $J$ Postgrad Med 2007;53:102-7

18. Kunik ME, Roundy K, Veazey C, Souchek J, 
Richardson P,Wray NP, et al. Surprisingly high prevalence of anxiety and depression in chronic breathing disorders. Chest 2005;127:1205-11.

19. Solano JP, Gomes B, Higginson IJ.A comparison of symptom prevalence in far advanced cancer, AIDS, heart disease, and chronic obstructive pulmonary diseases and renal disease. J Pain Symptom Manage 2006;31:58-69.

20. Manen JGV, Bindels PJE, Dekker FW, Jzermans CJI, Zee JSV, Schadé E. Risk of depression in patients with chronic obstructive pulmonary disease and its determinants. Thorax 2002;57:412-6.

21. Wagena EJ, Arrindell WA, Wouters EFM, Schayck CPV. Are patients with COPD psychologically distressed? Eur Respir J 2005;26:242.

22. Radloff LS. The CES-D scale: a self-report depression scale for research in the general population. Appl Psychol Meas 1977;1:385-401.
23. Derogatis LR, Savitz KL. The SCL-90-R and the Brief Symptom Inventory (BSI) in Primary Care In: ME Maruish, ed. Handbook of psychological assessment in primary care settings. Volume 236. Mahwah, NJ: Lawrence Erlbaum Associates, 2000. pp 297-334.

24. Schane RE, Walter LC, Dinno A, Covinsky KE, Woodruff PG. Prevalence and risk factors for depressive symptoms in persons with chronic obstructive pulmonary disease. J Gen Intern Med 2008;23:1757-62.

25. Boden JM, Fergusson DM. Alcohol and depression. Addiction 2011;106:906-14.

26. Tabak C, Smit HA, Heederik D, Ocké MC, Kromhout D. Diet and chronic obstructive pulmonary disease: independent beneficial effects of fruits, whole grains, and alcohol (The MORGEN study). Clin Exp Allergy 2001;31:747-55. 